\title{
Ensanchando el Presente
}

\section{Widening the Present}

\author{
Mario Alberto Méndez Ramírez \\ Magister en Educación por el Arte. Decano de la Facultad de Artes Visuales. \\ Universidad Nueva León de Monte Rey. México. \\ mario.mendez@uanl.mx
}

\section{Resumen}

El texto que se presenta a continuación es el resultado de un trabajo reflexivo que derivó de mi participación como jurado en la $6^{\mathbf{a}}$ Bienal Internacional de Arte Visual Universitario que convocó la Facultad de Artes de la Universidad Autónoma del Estado de México. Esta reflexión fue un ejercicio importante para complementar la decisión que como jurados tomamos Nicole Everaert - Desmedt de Bélgica; Pilar Villela Mascaró del Distrito Federal y Yo, ya que se nos pidió que lo presentáramos ante un público que estaba conformado en parte por algunos participantes de la Bienal y por la comunidad académica de la institución organizadora del evento. En este sentido, espero que las reflexiones que aquí se presentan sean de alguna utilidad para el análisis de los procesos de legitimación que en muchas ocasiones quedan en la oscuridad y que por lo tanto, mitifican el valor de las obras de arte y el arte mismo.

\section{Abstract}

The text to be presented next is the result of a reflective work originated in my participation as a jury in the 6th International Biennial of University Visual Art, convened by the School of Arts of the Autonomous University of Mexico State. This reflection was an important exercise to complement the decision which, as juries, took Nicole Everaert - Desmedt from Belgium; Pilar Villela Mascaró from the Federal District, and myself, since we were asked for it to be presented before an audience, partially comprised of some participants of the Biennial and the academic community of the institution organizing the event. In that sense, I hope that the reflections presented in here to be of some utility for the analysis of the processes of legitimation that in many occasions remain in the dark and therefore, mythologize the value of the works of art and the art itself.

\section{El Trabajo de Jurado}

Como lo expresé en el catálogo de la sexta emisión de la Bienal Internacional de Arte Visual Universitario, a la cual se me invitó como jurado ${ }^{1}$; intentar hacer un juicio selectivo de trabajos artísticos puede ser un ir y venir entre ideales y obras concretas. Siempre un ir y venir problemático, ya que nunca se vuelve al mismo sitio; ni el ideal es el mismo después de ver la obra, ni la obra es igual después de acudir al ideal en busca de criterios para evaluarla. En dinámicas como ésta, es que siempre está actualizándose de manera pragmática el propio concepto de lo artístico.

El juicio de selección de un jurado es un ejercicio de interpretación que se suma a la infinidad de lecturas con las que la recepción complementa las obras. Sin embargo existe una diferencia técnica entre la lectura del jurado y la que pudiera hacer un espectador ocasional. El primero, el juicio del jurado, es una interpretación que se objetiviza y circula socialmente al menos de dos maneras: como texto escrito, y/o en la acción de distinguir institucionalmente a ciertas obras sobre otras. En cambio, el juicio del espectador ocasional, muchas de las veces se queda en la subjetividad. La diferencia es pues, su objetivación y su circulación pública, que se dan desde un lugar privilegiado en cierta medida por la institución del arte.

Para cumplir estas condiciones, este tipo de juicio exige ser congelado, ya que en lo cotidiano, cualquier juicio es dinámico. Como toda interpretación, depende de contextos y circunstancias, por lo que siempre es probable que cambie en los diferentes momentos y ambientes en los que se ejerza. Sin embargo, a los jurados se nos pide que tomemos una decisión y

1 - "Ir y venir" Mario Méndez, incluido en: Catálogo de la sexta emisión de la Bienal Internacional de Arte Visual Universitario (2013). 
que establezcamos un juicio que trascienda su circunstancia y su contexto.

Por otra parte, el traslado del juicio a un texto, exige también una argumentación. Una argumentación en la gramática del logos, en la que siempre se corre el riesgo de la tergiversación. Y sumando otros riesgos, están también los de la ceguera o sesgo que es condición inalienable de la expresión de cualquier punto de vista. Ceguera hacia lo emergente, hacia lo silenciado o desplazado, o simplemente hacia lo que nuestros ojos, mal aconsejados por nuestras ideas, no pueden ver.

Con todos estos asegunes y más, una de las labores que desempeña la tarea objetivada y pública de un jurado es la de la mediación. Esta lectura legitimante, emitida desde un lugar privilegiado que le otorga alguno de los intersticios de la institución artística, se adhiere a la obra como otro de sus elementos constitutivos que serán considerados para sus recepciones futuras. De esta manera, después de ser premiada una obra, uno de sus interpretantes será el de "ganó en la bienal". Es así que los juicios objetivados y públicos de un jurado contribuyen en cierto sentido a la conformación de comunidades de recepción, y de alguna manera también, constituyen formas de producción de lo artístico.

Estas formas de producción de lo artístico no se dan solamente debido al trabajo de los jurados, sino más bien, se deben a la acción institucional que el fenómeno de la bienal significa. Con lo que se espera o se prevé, que se detone un cierto tipo de respuestas y reacciones que actualizan algunos de los posibles rumbos de transformación de las prácticas artísticas contemporáneas. Estableciendo un diálogo, una discusión o una disputa, que algún tipo de efecto tendrá en la producción futura de quienes han participado.

Creo que ésta dinámica detonada por la bienal y todo lo que ésta constituye: su convocatoria, la selección realizada y la exhibición de las obras; es una de sus principales finalidades. No entendida como una acción asertiva y planificada cuyos resultados se conozcan o se establezcan de antemano, sino como un movimiento inicial que provocará dinámicas futuras en diferentes direcciones.

Los resultados pueden ser más o menos convenientes, no lo sabemos, lo que sí creemos es que es conveniente el movimiento que se detonó. El marco académico en el que desarrolla el evento, nos permite suponer que lo que de aquí derive es valioso, no sólo por sus resultados, sino sobre todo, por los esquemas en que se desenvuelve, que son los del diálogo y la reflexión académica.

\section{Los Criterios de los Jurados}

En el catálogo referido, (de la sexta emisión de la Bienal Internacional de Arte) los jurados nos dimos a la tarea de explicitar en un breve texto, algunas de las ideas de las que partimos para realizar el trabajo que se nos encomendó. A continuación recordaré sucintamente lo escrito por cada uno de nosotros, y por mi parte, trataré de desarrollar un poco más las ideas que ahí presenté ${ }^{2}$.

\section{Nicole Everaert - Desmedt}

Nicole escribió acerca de lo que llamó su "método de selección", y comentó que basó dicho método principalmente en dos criterios: "la pertinencia de la pieza con respecto a los temas de la Bienal... y su carácter efectivamente artístico." ${ }^{3}$

Al referirse a "la comunicación artística" expresa de manera clara lo siguiente:

"seleccioné las piezas que me parecían adecuadas para provocar en el receptor una interpretación artística. Me refiero a mi modelo de la comunicación artística, elaborado a la luz del pensamiento semiótico de Charles Sanders Peirce. Considero que una obra de arte, más que un objeto es un proceso... Un proceso por el que una cualidad, una emoción (una primeridad según Peirce) es captada por el artista, parcialmente materializada en su obra (nunca puede materializarse completamente), y vuelta inteligible, dada a pensar al receptor."4

Por otra parte, Nicole expresa que al revisar las obras que le fueron enviadas, realzó algunas líneas maestras que se desprendían del conjunto del catálogo, las que definió de la siguiente manera:

"Llegué a distinguir obras que presentan:

1.- Los aspectos negativos de la globalización

2.- Los aspectos positivos de la globalización.

3.- Los aspectos negativos de las tecnologías

4.- La explotación positiva de las tecnologías.

5.- La tradición transformada por la globalización"5

Y termina utilizando los dos criterios que estableció para hacerse las siguientes preguntas sobre las obras: "¿Está la obra bien en relación con los temas de la Bienal?; ¿Nos hace entender algo al respecto?; ¿Es susceptible la obra de provocar una comunicación artística? Es decir; Consigue la obra: Captar la 'primeridad'... materializarla... y volverla inteligible para el receptor? Dicho de otra forma, ¿Nos hace pensar a partir de una emoción?"

Me parece importante destacar la claridad de los planteamientos de Nicole, claridad que también fue

2 - Los jurados de la sexta emisión de la Bienal Internacional de Arte Visual Universitario fueron: Nicole Everaert - Desmedt de Bélgica; Pilar Villela Mascaró del Distrito Federal y Mario Alberto Méndez Ramírez de Nuevo León, y autor de éste texto.

3 - Catálogo de la sexta emisión de la Bienal Internacional de Arte Visual Universitario (2013) p. 32.

4 - lbíd.

5 - Ibíd.p. 32, 33, 34

6 - Ibíd. p. 35 
evidente en los procesos de diálogo que fueron necesarios para las decisiones definitivas.

\section{Pilar Villela Mascaró}

Pilar inicia haciendo una reflexión general sobre la bienal; Primeramente nos dice que los diferentes modelos históricos de la enseñanza artística siguen coexistiendo en los programas universitarios actuales. El modelo del taller, el de la educación visual, el modelo neoliberal y el modelo, digámosle "universitario" que es el que vincula a las artes con otras disciplinas y se traduce en el estudio de la imagen y otro tipo de discursos académicos que de esto han derivado.

Esta reflexión le permite hacer una observación específica al decirnos que "Esta convivencia (la de los diversos modelos), así como la dificultad de integrar los diferentes modelos a la producción, resulta harto evidente en las obras presentadas para esta bienal"7.

Relaciona después este comentario inicial con la expresión clara de uno de sus criterios, al decir "Precisamente por lo dicho en un principio, porque creo que la potencia de la educación artística no es normativa, sino conflictiva, he preferido las obras que, en mi opinión, escenifican esta confrontación"'. De lo que interpreto yo, que el diálogo crítico del estudiante hacia los modelos en los que fue formado es uno de los criterios que definieron su juicio.

En otra parte del texto Pilar expresa en relación a sus criterios lo siguiente:

"he intentado elegir aquellas obras que, independientemente de los medios y la técnica que empleen, tienen cierto nivel de factura, problematizan su propio medio o son conscientes de él y, sobre todo, logran entablar un diálogo con la realidad presente ${ }^{\prime \prime}$.

Estas ideas fueron muy útiles cuando nos acercábamos a las obras para evaluarlas in-situ. Ese nivel de factura al que se refirió, era un elemento muy evidente para diferenciar entre trabajos que reflejaban no sólo la dedicación, sino el dominio mismo de los medios utilizados para su construcción. Dominio que, como sabemos, no se refiere tan sólo a habilidades técnicas y manuales, sino sobre todo a gramáticas y lenguajes.

Relacionado con lo anterior, creo que los tres coincidimos en un comentario que Pilar expresó en el debate de selección. Refiriéndose a la percepción de un cierto divorcio entre la factura y el concepto; es decir que en algunas piezas era evidente la preocupación por una buena factura, pero que en las que así sucedía, el concepto era por lo regular débil o incipiente; y en contraste, había piezas con conceptos interesantes carentes de una buena ejecución.
Casi al final de su escrito, Pilar comenta algo que parece obvio pero no por eso es menos importante, que es el hecho de que "el resultado final no proviene de una decisión individual, sino del acuerdo y el debate razonado con mis colegas"10.

Antes de abordar lo relativo a mis criterios, me parece importante decir, que ese debate razonado al que se refirió Pilar, se dio de una manera muy fluida, escuchándonos e intentando complementar los criterios previos de cada uno con las perspectivas de los otros. En este sentido, también agradezco a mis dos compañeras, Nicole y Pilar, el profesionalismo, la claridad y la actitud constructiva con la que siempre se comportaron.

\section{Mario Méndez}

En mi caso, expresé en el texto del catálogo varios criterios, y en este texto quisiera ahondar un poco en algunos de éstos. Recientemente revisé un texto en el que se discutía sobre la aparente oposición entre el aspecto poético y el político de las obras ${ }^{11}$. Con lo poético, y arriesgando mucho la síntesis, entendemos entre otras cosas, la elusividad de la obra a cualquier traducción que no sea ella misma, su negación a ser agotada en la literalidad y su resistencia al deseo de posesión por parte del receptor. Y sumando el concepto de Nicole, también lo entendemos como ese proceso en el que una emoción o cualidad es materializada y dada a pensar al receptor, que ella define como "comunicación artística". Y por otro lado, con lo político, nos referimos a su fuerza de transformación social y su toma de postura ideológica.

Me pareció esclarecedora una de las ideas que en ese texto se expresaba; decía: "Lejos de constituir la antítesis de lo político, el placer puede ser el vehículo perfecto para expresar un compromiso político"12. De lo cual yo derivo, que la eficacia ideológica y social de una obra está mayormente fundada en sus formas estéticas, no en sus contenidos explícitos.

La poética de la obra es pues, uno de los medios más eficaces para el trabajo político. De hecho, actualmente, es en la modelación de las subjetividades por medio de la producción estético-simbólica en dónde se realizan las más cruentas batallas políticas.

Esta forma de lo político- poético, tiene principalmente dos filosas estrategias; por una parte, presenta las ideologías como naturalizadas, exentas de lo histórico y lo social; y por el otro, a manera de "caballo de Troya" las introduce silenciosamente para hacernos creer que provienen de nuestro más profundo interior, que son parte de nuestra esencia individual, que son nuestro gusto, trabajando desde dentro. Entonces, lo estético puede ser la estrategia perversa para la dominación,

10-lbíd.

11 - "10 curators in conversation" incluido en Cream 3 (2003).

12 - "Far from being antithetical to politics, pleasure can be the perfect vehicle for political commitment" Ibíd: p. 7. La traducción es nuestra. 
pero también el único dispositivo crítico para evidenciar sus propias formas de operar.

En este sentido, nos parece valioso el trabajo artístico que por un lado, evidencia la dominación simbólica inscrita en la propia lógica de los códigos, y por el otro, quiéralo o no, enuncia su propia ideología; no en la literalidad de sus mensajes o temas, sino en el propio trabajo de sus medios y de los medios de la cultura en general. A ese trabajo poético-político se suma también como acto más político que poético, el trabajo de selección del jurado, y es importante estar conscientes de ello y hacerlo asumiendo esta responsabilidad.

En estrecha relación con el carácter político de las obras, otro de los valores que buscamos es el de la procuración de alumbramiento de lo inexistente, no sólo de lo inexistente por fantástico e imaginario, sino de lo que ha sido excluido, segregado o negado. El acto de comprensión hacia lo que la representación hegemónica ha negado su existencia, por su etnia, su género, su clase, su desvío de la norma su diferencia o su improductividad mercantil.

La lucha por abrir espacios posibles de existencia para tanta experiencia negada, y por lo tanto, para la ampliación de lo real, es un trabajo digno de lo artístico. Es digna de lo artístico, la tarea solidaria para la emancipación, en vez de la acción colonizante de ordenación y manipulación en representaciones disminuidas o jerarquizantes. La obra que se esfuerza para decir lo que no ha sido, para desde las propias gramáticas vigentes, intentar transformaciones pragmáticas sin que se pierdan en la inefabilidad o en lo críptico. En busca no sólo de la expresión de los dolores del artista, sino sobre todo, en busca del alumbramiento de experiencias de muchos, experiencias que se han quedado en estado gelatinoso, sin cuajar en la realidad de lo representado, ese tipo de obras nos parecen dignas de atención.

\section{Legitimación Ascendente}

A los procesos de legitimación que se logran con eventos institucionales como esta bienal, podríamos llamarles procesos de legitimación descendente. Con esto queremos decir que la legitimidad de la obra se obtiene por la decisión de agentes que ocupan, por razones circunstanciales, un lugar privilegiado que los posibilita a ejercer la acción de legitimación. En este caso, un jurado que considera que tales o cuales obras destacan de las demás y son acreedoras de reconocimiento público.

Sin embargo, para la obra de hoy (intencionalmente no uso el término contemporáneo) sería más importante la búsqueda de procesos de legitimación ascendente, es decir aquella legitimación que se lograría por el hecho de que alguno o algunos de los grupos que conforman la sociedad, se vean involucrados en ella. $\mathrm{O}$ mejor dicho, no se trata ya de buscar estos procesos de legitimación ascendente al hacer participar a la sociedad, sino que el trabajo artístico, bajo este concepto, se entiende antes que nada, como una práctica legítimamente social, que nace enredada con otras prácticas necesarias, a veces aupada de manera imperceptible en la inalienable simbolicidad de todo lo humano. Que no cobra sentido ni necesita traducción alguna, sino que nace con el sentido que le otorga su carácter necesario. Que su perceptibilidad o si se quiere, su traducción, fulguran fantasmalmente en la posibilidad de conciencia que arrastra por su carácter reflexivo, más que por alguna pretensión de espectacularización.

Ahora, estos procesos de legitimación ascendente deben ser los verdaderos jurados, y las convocatorias para participar en este otro tipo de eventos, circulan en el aire, en la enrarecida atmósfera de lo social y de lo humano. Y también más allá, en los terrenos de lo biológico y lo mineral, del Todo del que formamos parte.

\section{Lo universitario}

En una oportunidad anterior expresé la necesidad de reflexionar sobre lo que significa "lo universitario", sobre todo tomando en cuenta que esta bienal se sitúa en ese contexto ${ }^{13}$. En aquella ocasión comentaba algunas ideas sobre lo universitario como un tipo de producción sui-géneris que según Bourdieu no es propiamente producción, sino sobre todo, producción de capacidades de producción. "Estudiar no es producir, sino producirse como alguien capaz de producir $^{\text {"14. }}$. Por otro lado, también en aquella ocasión nos hacíamos preguntas acerca del poder de convocatoria de este tipo de eventos, y por lo tanto de su representatividad. En este sentido, me gustaría compartir primero algunas de las estadísticas surgidas en esta ocasión para revisar la idea de representatividad, para después permitirme otra reflexión sobre lo universitario, ahora desde otro autor.

\section{Estadísticas}

En esta sexta emisión, hubo más de 500 participantes con más de 1000 proyectos de 17 países $^{15}$. De México se recibió obra proveniente de 19 entidades federativas. Aproximadamente el $90 \%$ de los inscritos fueron del país, y el restante $10 \%$ extranjeros.

Los egresados se aproximaron al 50\% del total, siguiéndole los estudiantes con poco más del $35 \%$, y con el restante 15\%, los profesores. Tomando en cuenta, tanto lo nacional como lo extranjero, fueron más de 80 universidades las que se dieron cita.

13 - Mario Méndez "El acontecimiento y el vestigio, reflexiones sobre las bienales" incluido en Miranda y Villalobos (2013).

14 - Bourdieu p. 2004; p. 84.

15 - Los datos estadísticos fueron proporcionados por los organizadores de la sexta emisión de la Bienal Internacional de Arte Visual Universitario. 
Al revisar estos datos, creo que sí podríamos hablar de un alto grado de representatividad, sobre todo, a nivel nacional. Es entendible que la mayor participación haya sido del país, sin embargo, de seguir consolidándose el evento, podría lograrse un notorio aumento de la participación de otros lugares, sobre todo porque, como sabemos, gracias a la tecnología, cada vez es más fácil la difusión y la comunicación entre sitios distantes.

Nos llama la atención el alto porcentaje de participación de egresados, y nos permite aventurar la idea de que para los egresados de carreras de artes, una de las formas importantes de dar a conocer su trabajo y de agenciarse recursos para la producción, siguen siendo las convocatorias como ésta. Lo cual es importante para la organización de la bienal en dos sentidos al menos, por un lado, su convocatoria es atractiva no sólo para quienes están en formación, sino para aquellos que ya se desenvuelven profesionalmente con su trabajo artístico. Y por otro lado, la bienal significa para los egresados, una opción más, ante el mercado del arte, al incentivar una producción libre de demandas comerciales. Por lo que, libre de éstas se puede tener un carácter más experimental y crítico.

Otro dato interesante es que la mayoría de los trabajos son producciones individuales, siendo sólo colectivas cerca del 2\% de las obras. En lo personal, me hubiera gustado ver mayor cantidad de trabajo grupal, sobre todo porque, como ya lo expresé, me parece importante la obra participativa e interdisciplinaria, características que se ven más seguido en los trabajos hechos de manera colectiva.

\section{Lo Pluriversitario}

Dejando de lado las estadísticas, quisiera compartir, otras ideas sobre lo universitario que encontré en un texto de Boaventura de Sousa, un interesante académico portugués ${ }^{16}$. Boaventura nos propone el término de "lo pluriversitario" para sustituir el de "lo universitario". Con este nuevo término se refiere al conocimiento que se crea por un proceso de intercambio entre académicos y usuarios, en el que la sociedad deja de ser objeto de las interpelaciones de los universitarios para convertirse en sujeto que los interpela.

Nos contextualiza diciendo que el ethos que conformó históricamente a las universidades públicas "fue predominantemente disciplinario, y que su autonomía impuso un proceso de producción, hasta cierto grado, descontextualizado en relación con las urgencias de la cotidianeidad de las sociedades. Por estas razones, se traducía la autonomía de los académicos en cierta irresponsabilidad social"17.
Sin embargo Boaventura percibe que este ethos y este modelo de acción de las universidades ha estado transformándose durante la última década (el texto fue editado en el 2006), y es a esta transformación a la que denomina como el paso de lo universitario a lo pluriversitario ${ }^{18}$.

Esto se podría malentender, sólo como una adecuación de la universidad a las demandas mercantiles de profesionales necesarios para la producción económica. Pero no sólo es ahí en donde la universidad se está abriendo a lo social, sino que se está dando ya un tipo de trabajo cooperativo y solidario mediante asociaciones con: organizaciones no gubernamentales, movimientos sociales, sindicatos, grupos sociales especialmente vulnerables, comunidades populares, grupos de ciudadanos críticos y activos, entre otros ${ }^{19}$. Por lo que termina diciendo el autor que: "El conocimiento pluriversitario sustituye la unilateralidad por la interactividad"20.

Este breve asomo a los cambios que sufren actualmente las universidades, desde el punto de vista de este autor, nos permite volver a hacer hincapié en las ideas expresadas líneas arriba, sobre la necesidad de que las prácticas artísticas procuren tareas políticas y sociales. Sin abandonar la importancia del hacer propio de lo artístico.

Aunque lo que diré a continuación se expresa en todas las épocas, En la nuestra, sentimos que estamos en un momento especial de transformación social. Y al parecer, uno de los signos que nos hacen percibir esto, es el de la desaparición de las fronteras. Esta misma bienal eligió como uno de sus ejes temáticos el fenómeno de la globalización.

Paradójicamente no son las fronteras geográficas las que se están desvaneciendo, incluso en algunos casos más que debilitarse, tienden a reforzarse para evitar el trasvase de uno a otro lado. $O$ sólo se desaparecen para el trasiego comercial, no el de las personas.

En este sentido, y tomando el análisis que sobre la idea de globalización hace Boaventura de Souza, podríamos decir lo siguiente ${ }^{21}$ : Lo que sucede en los fenómenos de las globalizaciones ${ }^{22}$, es el envite de diferentes localidades, en el cual, las más fuertes dominan haciendo que sus prácticas y sus intereses sean asumidas por las otras localidades, convirtiéndose así en prácticas globalizadas. $\mathrm{Y}$ etiquetando como prácticas locales aquellas que se dan en las culturas o grupos dominados. Esta idea es compleja en el sentido de que, como sabemos, algunas prácticas de culturas sometidas también se globalizan, pero se globalizan como formas culturales estereotipadas y etiquetadas

16 - Santos, Boaventura de Souza (2006)

17 -Ibíd. p. 37.

18 -Tbíd. p. 38

19-Ibíd. p. 39.

20 - Tbíd.

21 - Santos, Boaventura de Souza (2009) p. 230.

22 - La idea de que hay más de una globalización también es expresada por el autor en estas mismas páginas. 
de exotismos. Sin embargo, cuando son las prácticas de los grupos dominantes las que logran su trascendencia global, éstas se entienden como universales o prestigiosas.

Además, otro de los elementos que hacen compleja esta dinámica es el de la deslocalización de los grupos de poder, es decir, que dichos grupos ya no pertenecen propiamente a culturas nacionales específicas, sino que están distribuidos por el orbe constituyendo grupos deslocalizados. Y por último, como sabemos, en cualquier relación de dominador-dominado, la transformación es mutua, en diferentes dimensiones y sentidos.

Dicho lo anterior, me parece importante comentar lo que sucede en el ámbito del conocimiento. Es en este terreno en dónde se presenta como estratégica la construcción de una ecología de los saberes, esta estrategia busca disminuir las fronteras entre los diferentes tipos de conocimiento. Procurando que se respeten y complementen las diferentes sapiencias que se expresan en toda práctica social. Una ecología entendida como un sistema en dónde la ciencia no se arrogue la exclusividad del conocimiento, lanzando a otros tipos de saberes, como el artístico y el tradicional a la primitividad, a lo ridículo o a lo tangencial, sino que sea sólo, otra de las diversas formas de construir la realidad.

En las prácticas artísticas son ya comunes los trabajos híbridos en el que se complementan las diferentes artes. En las disciplinas científicas, sabemos ya de las tendencias multi, inter y transdisciplinarias. $Y$ entre las artes y las ciencias, se conocen suficientemente los trabajos cooperativos.

Creemos que es necesario, seguir trabajando en este sentido. En la comprensión de la interdependencia necesaria de todo con todo, en la búsqueda de valores comunes a las prácticas artísticas, científicas y cotidianas.
Las problemáticas que hoy nos aquejan requieren de enfoques holísticos en los que reunamos todos los saberes con los que contamos, y uno de ellos es el saber de lo artístico.

Las universidades son lugares privilegiados para la participación activa y estratégica en las grandes transformaciones que se avecinan. Y sospecho, que lo artístico también lo es, pero un "artístico" renovado por la sensatez, la comprensión y la solidaridad. No aquel arte de brillos oropélicos, de retorcidas metafísicas o de asombrosas genialidades.

Para terminar, volveremos a apropiarnos una de las ideas de Boaventura de Sousa, y diremos con él, que no pensamos que el cambio deba situarse en el futuro, sino que lo importante es, ensanchar el presente ${ }^{23}$. Ensancharlo con la inclusión de todas las experiencias amplias y diversas que han sido disminuidas o negadas por la globalización hegemónica. Un ancho presente que también nos permita pensar en la construcción de diferentes futuros, no sólo aquellos determinados por la idea de desarrollo lineal presentada principalmente por el sistema mundo moderno-occidental, sino que nos permita aspirar a nuevos estadios de lo humano más incluyentes y equitativos, e insisto en que en esta enorme tarea, tenemos mano los universitarios.

\section{Referencias Bibliográficas}

AAVV (2003) Cream 3: contemporary art in culture. New York: Phaidon.

Bourdieu, Pierre (2004) Los herederos: los estudiantes y la cultura. Buenos Aires: Siglo XXI

Catálogo de la sexta emisión de la Bienal Internacional de Arte Visual Universitario (2013) Toluca: Universidad Autónoma del Estado de México.

Miranda y Villalobos (compiladores) (2013). Bienales de arte: referentes teóricos. Toluca: Universidad Autónoma del Estado de México.

Santos, Boaventura de Souza (2006) La Universidad en el siglo XXI: para una reforma democrática y emancipadora de la universidad. La Habana: Fondo Editorial Casa de las Américas.

Santos, Boaventura de Souza (2009) Una epistemología del Sur. México, Siglo XXI, CLACSO.

23 - Santos, Boaventura de Souza (2009). 